\title{
Topographic and Hydrologic Analyses using Geographic Information System (GIS): A Case Study of Karbala City-Iraq
}

\author{
Habeeb Ghdhaib Maarez ${ }^{1, a^{*}}$ and Hussein Sabah Jaber ${ }^{1, b}$ \\ ${ }^{1}$ Surveying Engineering Department, University of Baghdad, Baghdad, Iraq. \\ ah.maarez1412@coeng.uobahgdad.edu.iq, bhusseinsabah00@gmail.com
}

\begin{abstract}
Analyses are the power point of GIS because GIS can process and analyze different data such as spatial and attribute data, leading to obtaining new results for supporting decision-makers. This research aims to study two types of advanced analyses include; topographic and hydrologic analyses for the western part of Karbala in Iraq using GIS. The topographic analysis aims to know surface terrain and obtain the results of digital maps that show the simulation of the study area based on some methods and tools in GIS after creating DEM for study area from field survey methods such as slope, aspect, hill shades, and contour maps. After that, hydrologic analysis is done based on DEM of the study area, where this analysis gives digital maps that show the main and minor hydrological properties of the region, such as flow direction, flow accumulation, stream order, and basin maps. These analyses are very important for making decisions in studying the topographic and hydrologic properties of any region in Iraq, and the GIS technique offers a save in time, cost and efforts.
\end{abstract}

Keywords: GIS; DEM; topographic analyses, hydrological analyses.

\section{Introduction}

Iraq is considered one of the water-rich countries due to the presence of the two rivers (Tigris, Euphrates). The building of dams on the Tigris and the Euphrates and their tributaries by countries that originate or pass from them, such as Turkey and Syria, global climate change, and mismanagement of these resources are reasons leading to the scarcity of water in Iraq by the year 2040 [1]. Geographic information systems (GIS) are used to classify and analyze information and store it in databases [2]. The methods of obtaining data using GIS allowed geographers, engineers, and those interested in accessing for any part of the world, even those that are difficult to reach using traditional methods [3,4]. DEM is a three-dimensional representation of the earth's surface, and it is one of the easiest types of digital representation of the topography of the surface of the earth. Digital elevation models can be used in determining many topographic studies, for example, contour map, slope, aspect, and hill shade [5,6]. Also, hydrological studies of any study area include flow direction, water shade, stream order, and basins [7]. There are many ways to create a digital elevation model that differs in accuracy, time, and costs, such as satellite images, aerial photos, laser scanning, and field surveys [8]. The western part of Karbala is a part of the western plateau in Iraq that there is no surface water in this region [9]. In recent years, with the advancement of digital technology such as geographic information system and digital three-dimensional modeling, it encouraged many researchers to study the topographical and hydrological characteristics of such lands, which in turn helped many decision-makers to manage and secure water resources to encourage local people to use water in scientifically correct ways [10]. Hence, this research aims to study the topographic and hydrologic properties of the western part of Karbala city-Iraq using GIS technology to support decision makers with these because of GIS having the capability in low cost, save the efforts and time [11].

\section{Materials and Data Used}

Study Area. Karbala governorate is located between latitudes $31.75^{\circ}$ and $33.5^{\circ}$ north, and longitudes $43.2^{\circ}$ and $44.5^{\circ}$ east, and it is located in the center of Iraq with borders occupied by Babel Governorate from the east and northeast, Anbar governorate from the west and northwest, Najaf governorate from 
the south [9]. The study area is located in the southern part of the northern temperate zone situated at the end of the eastern end of the land area connected to the west with the desert climate, and the high temperatures in the summer may reach 50 degrees Celsius, but in the winter the temperatures drop to below zero degrees Celsius. The topographic surface of the study area is some of the sandy hills and valleys and some water complexes that consist of rainwater [12,13]. Figure 1 showed the location of the study area map (www.google.com).

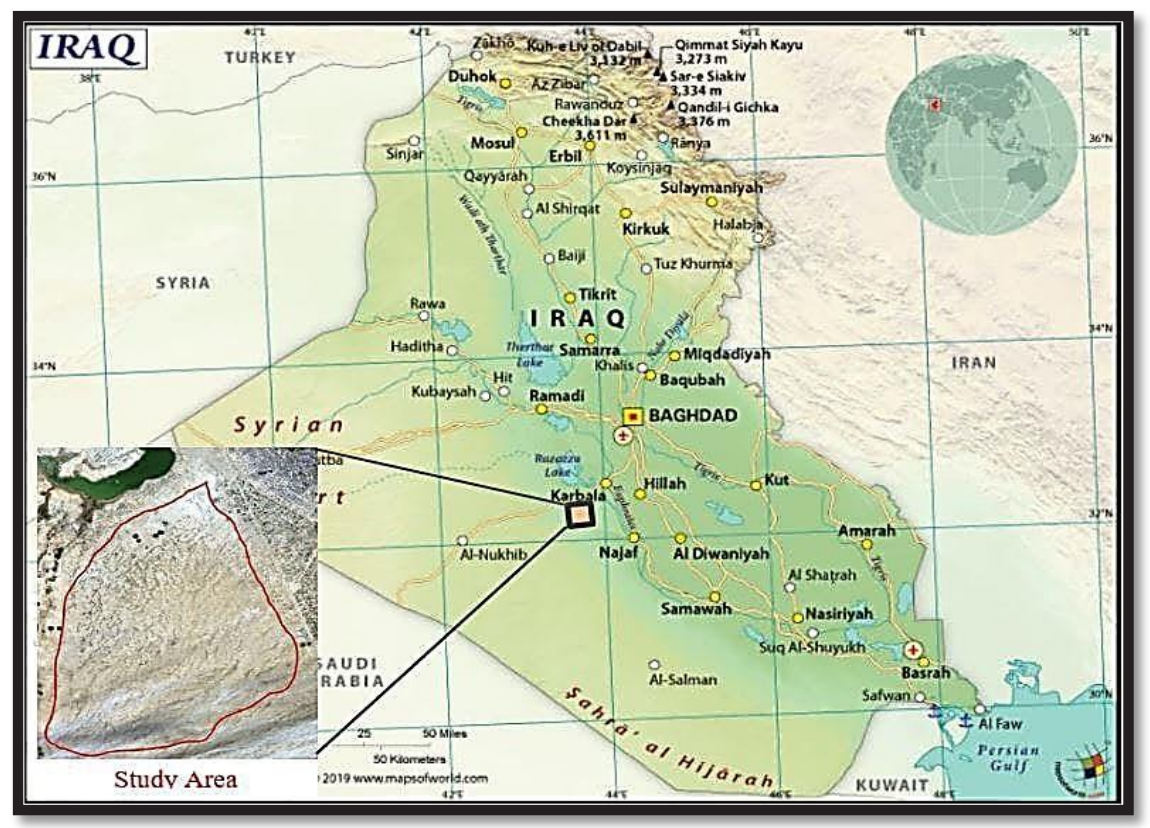

Figure 1. Location the study area map. (www.google.com).

Data Used. The collection of data for the study area, which are points that were observed in the field was the total number (400 points GPS )by using a handle GPS device with a geographic coordinate system and with an accuracy of this device for horizontal $( \pm 2-5 \mathrm{~m})$ and for vertical accuracy $(<10 \mathrm{~m})$ [14]. Table 1 shows some of the data from the field survey for the study area.

Methodology. Figure 2 shows the schematic of the research methodology. The study area's digital elevation model (DEM) was created using ArcGIS software 10.8 and from the data collected using the field survey as shown in Table 1 previously. To obtain a DEM close to the real surface, the points are condensed using the spatial interpolation method where the Inverse distance weighted (IDW) method was used that depends on the distance between the known point and the unknown points [15]. The accuracy of the DEM is less than about ten meters, which is more accurate than the free DEMs resolution available from satellites [16]. Figure 3 showed the production of DEM for the study area. The use of the field survey method in this research focuses on this technique in creating DEM for the study area and the work of all the required analyses and representing the topography of the study area. Also, several studies have proved the accuracy of the DEMs created from the field survey more accurate than the free DEMs available from satellites, and that field survey gives more visualization of the study area.

\section{Results and discussion}

Based on the DEM produced, the topographic and hydrologic analyses for the study area were done using Arc GIS as following:

Contour map. The contour map of the study area is produced from DEM using GIS as a vector layer with contour interval $(10 \mathrm{~m})$. The contour lines show that the surface terrains of the study area have the lowest altitude about $(30 \mathrm{~m})$ above sea level in the northwest, and the area continues to rise until 
it reaches the highest altitude $(130 \mathrm{~m})$ to the south. The average height approximately $(70 \mathrm{~m})$ as shown in Figure 4.

Table 1. Some of the data from field survey for the study area.

\begin{tabular}{|c|c|c|c|c|c|c|c|}
\hline Point & Lat. (degree) & Lon. (degree) & Elv. (m) & Point & Lat. (degree) & Lon. (degree) & Elv. (m) \\
\hline 1 & 32.23766 & 43.86108 & 125 & 26 & 32.28491 & 43.88812 & 113 \\
\hline 2 & 32.26834 & $43 . .80909$ & 125 & 27 & 32.31152 & 43.91805 & 106 \\
\hline 3 & 32.24422 & 43.88492 & 120 & 28 & 32.27993 & 43.84489 & 119 \\
\hline 4 & 32.25549 & 43.88762 & 115 & 29 & 32.30819 & 43.83492 & 115 \\
\hline 5 & 32.33187 & 43.81552 & 110 & 30 & 32.42791 & 43.84822 & 96 \\
\hline 6 & 32.26191 & 43.90546 & 110 & 31 & 32.42791 & 43.94798 & 84 \\
\hline 7 & 32.34400 & 43.81190 & 105 & 32 & 32.37470 & 43.98789 & 88 \\
\hline 8 & 32.27261 & 43.93258 & 100 & 33 & 32.28159 & 43.62541 & 86 \\
\hline 9 & 32.37898 & 43.81837 & 100 & 34 & 32.32316 & 43.63040 & 65 \\
\hline 10 & 32.21265 & 43.71344 & 95 & 35 & 32.35309 & 43.62874 & 56 \\
\hline 11 & 32.99684 & 43.82551 & 95 & 36 & 32.37969 & 43.63040 & 54 \\
\hline 12 & 32.28118 & 43.96114 & 90 & 37 & 32.47945 & 43.63539 & 60 \\
\hline 13 & 32.22622 & 43.70558 & 90 & 38 & 32.50273 & 43.64703 & 55 \\
\hline 14 & 32.22193 & 43.68274 & 85 & 39 & 32.52435 & 43.65700 & 48 \\
\hline 15 & 32.47106 & 43.82622 & 80 & 40 & 32.55428 & 43.66698 & 29 \\
\hline 16 & 32.21694 & 43.66204 & 75 & 41 & 32.56425 & 43.69358 & 29 \\
\hline 17 & 32.29760 & 43.99469 & 75 & 42 & 32.58919 & 43.74513 & 28 \\
\hline 18 & 32.27655 & 43.65764 & 70 & 43 & 32.56259 & 43.73682 & 28 \\
\hline 19 & 32.29831 & 44.05139 & 65 & 44 & 32.55095 & 43.71520 & 32 \\
\hline 20 & 32.31416 & 44.03181 & 60 & 45 & 32.53599 & 43.68693 & 40 \\
\hline 21 & 32.30488 & 44.02538 & 55 & 46 & 32.51603 & 43.67529 & 46 \\
\hline 22 & 32.55901 & 44.04751 & 48 & 47 & 32.48444 & 43.66199 & 56 \\
\hline 23 & 32.32872 & 4406679 & 43 & 48 & 32.45618 & 43.65368 & 63 \\
\hline 24 & 32.52217 & 43.63991 & 40 & 49 & 32.32149 & 43.65035 & 59 \\
\hline 25 & 32.51147 & 43.74913 & 35 & 50 & 32.29323 & 43.66199 & 79 \\
\hline
\end{tabular}

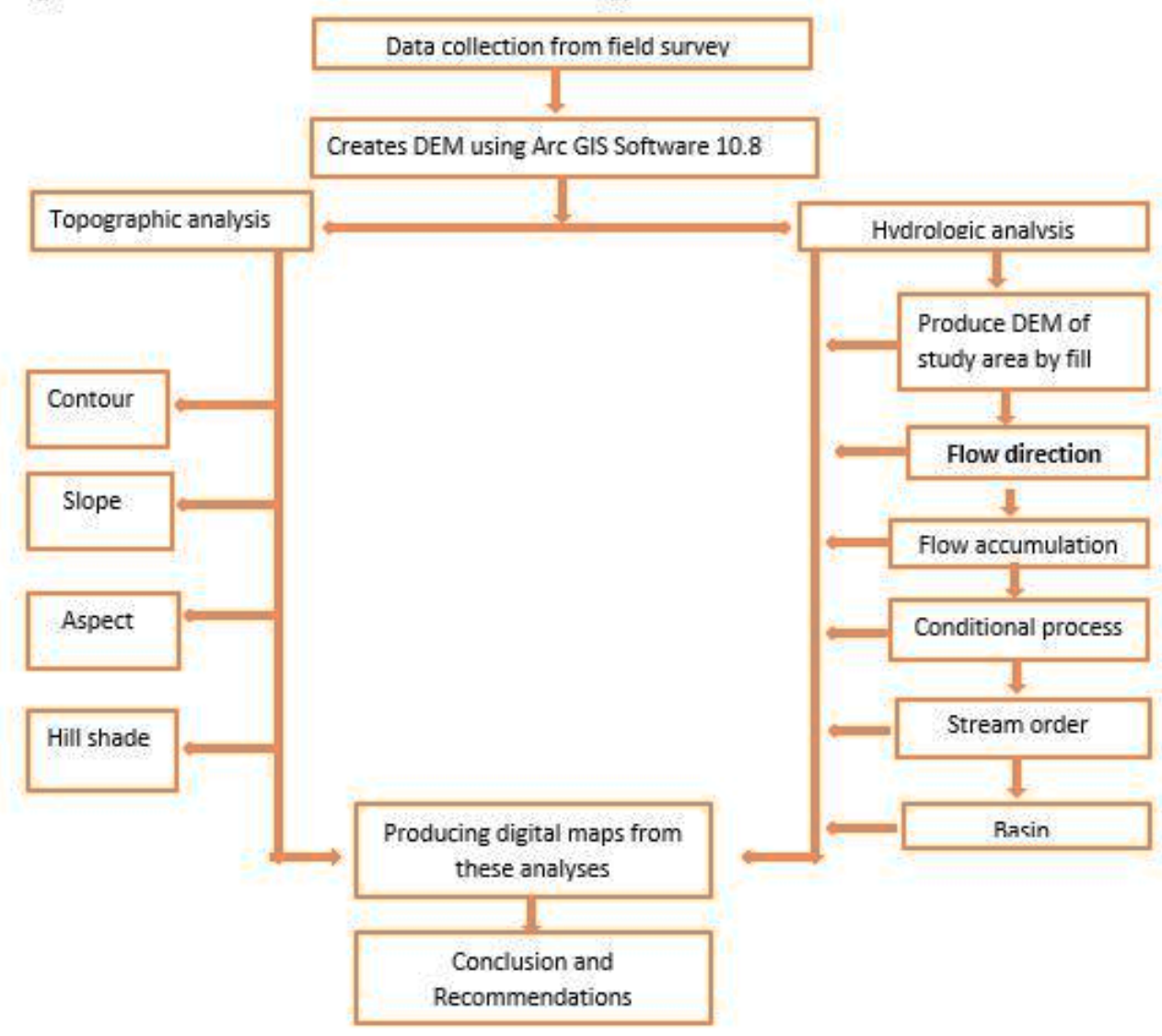

Figure 2. Schematic of the research methodology. 


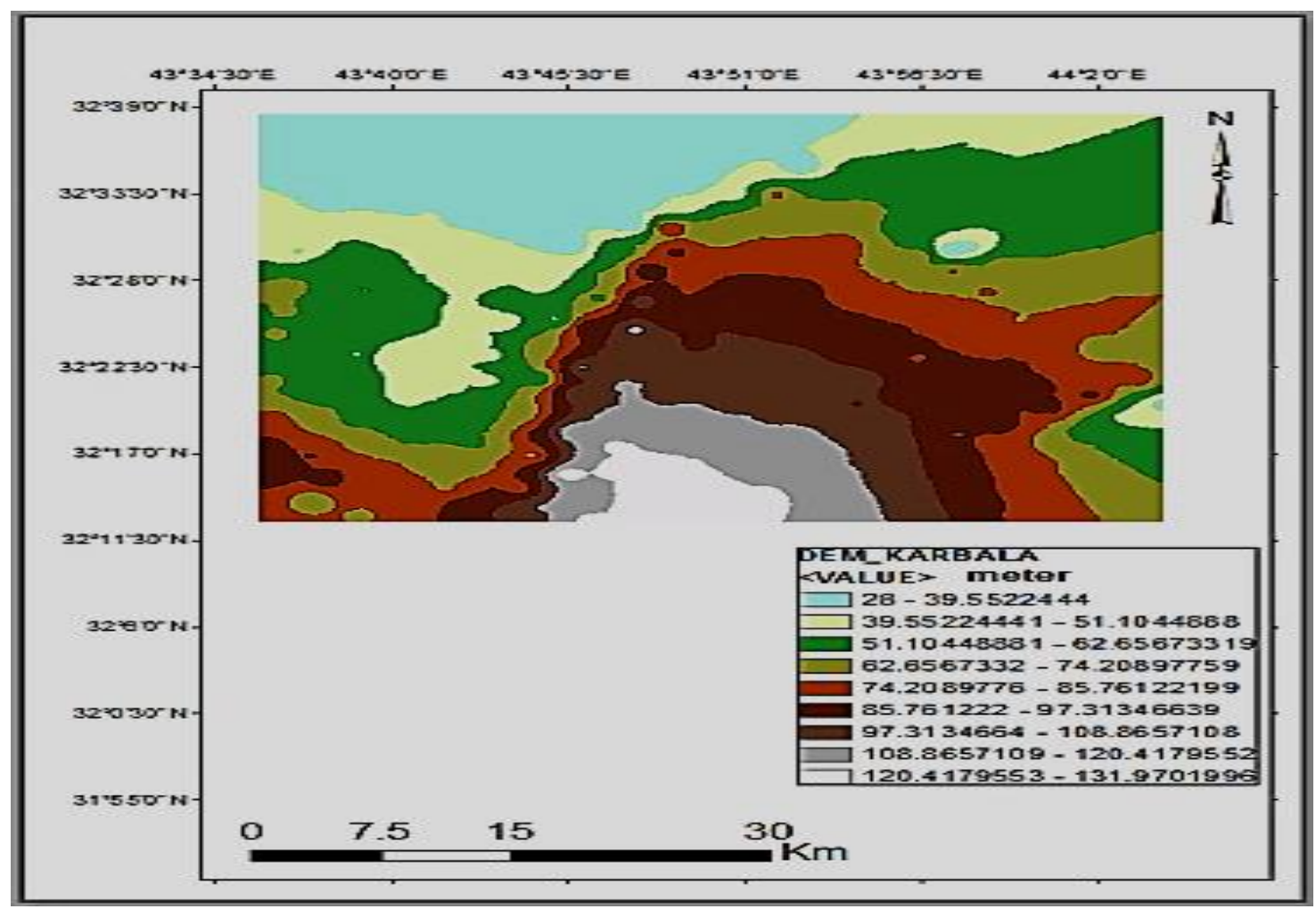

Figure 3: DEM of the study area.

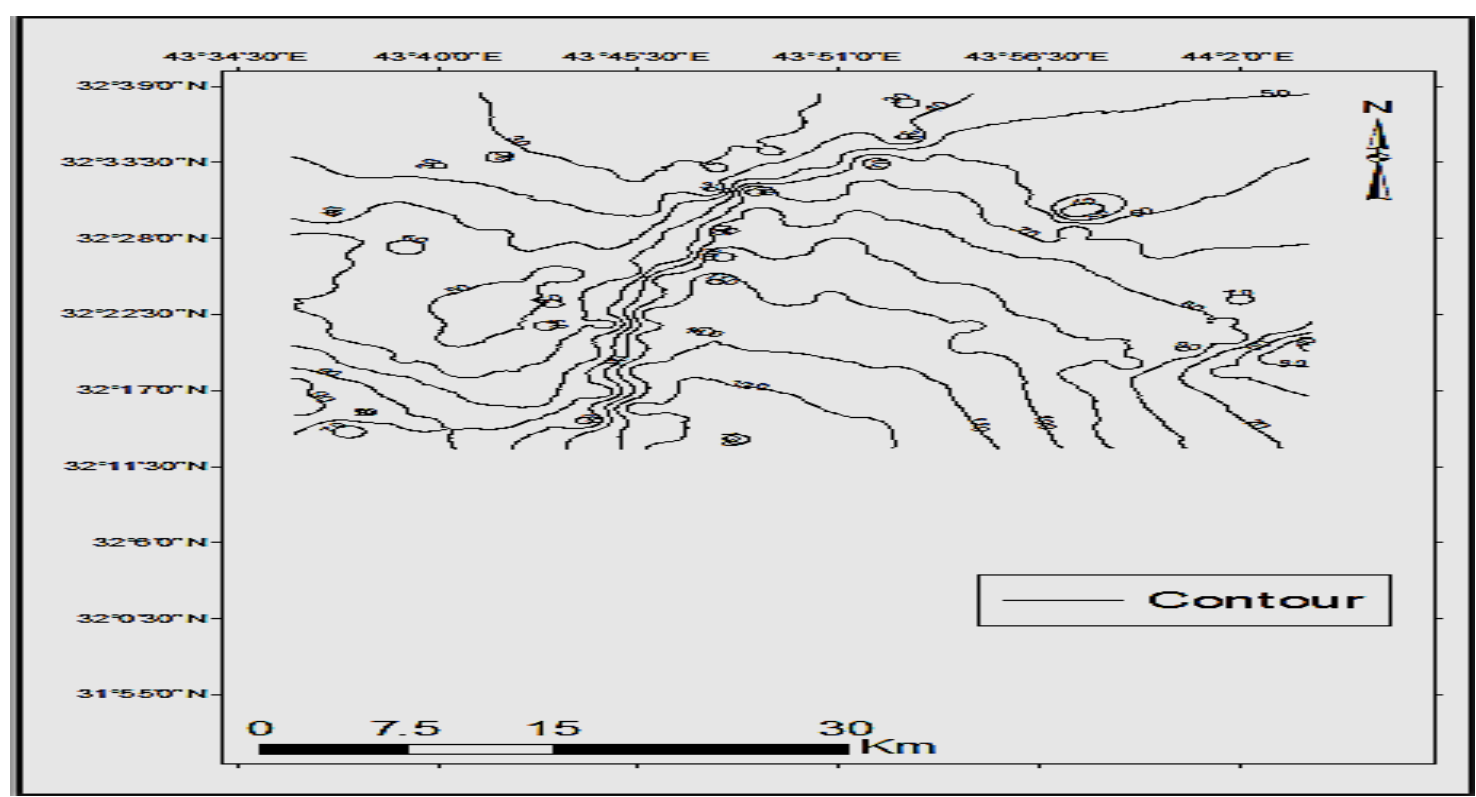

Figure 4. Contour map of the study area.

Slope map. After converting the projection of the digital elevation model for the study area from its units in degrees to units of length to produce a slope map for the study area and measured the slope map in degrees using the ArcGIS software10.8 as shown in Figure 5. From this map, it indicated that the low slope is equal ( 0 degrees $)$ and the high slope is equal ( 2.18 degree $)$, and the slope mean for the study area is approximately equal ( 0.2 degrees). 


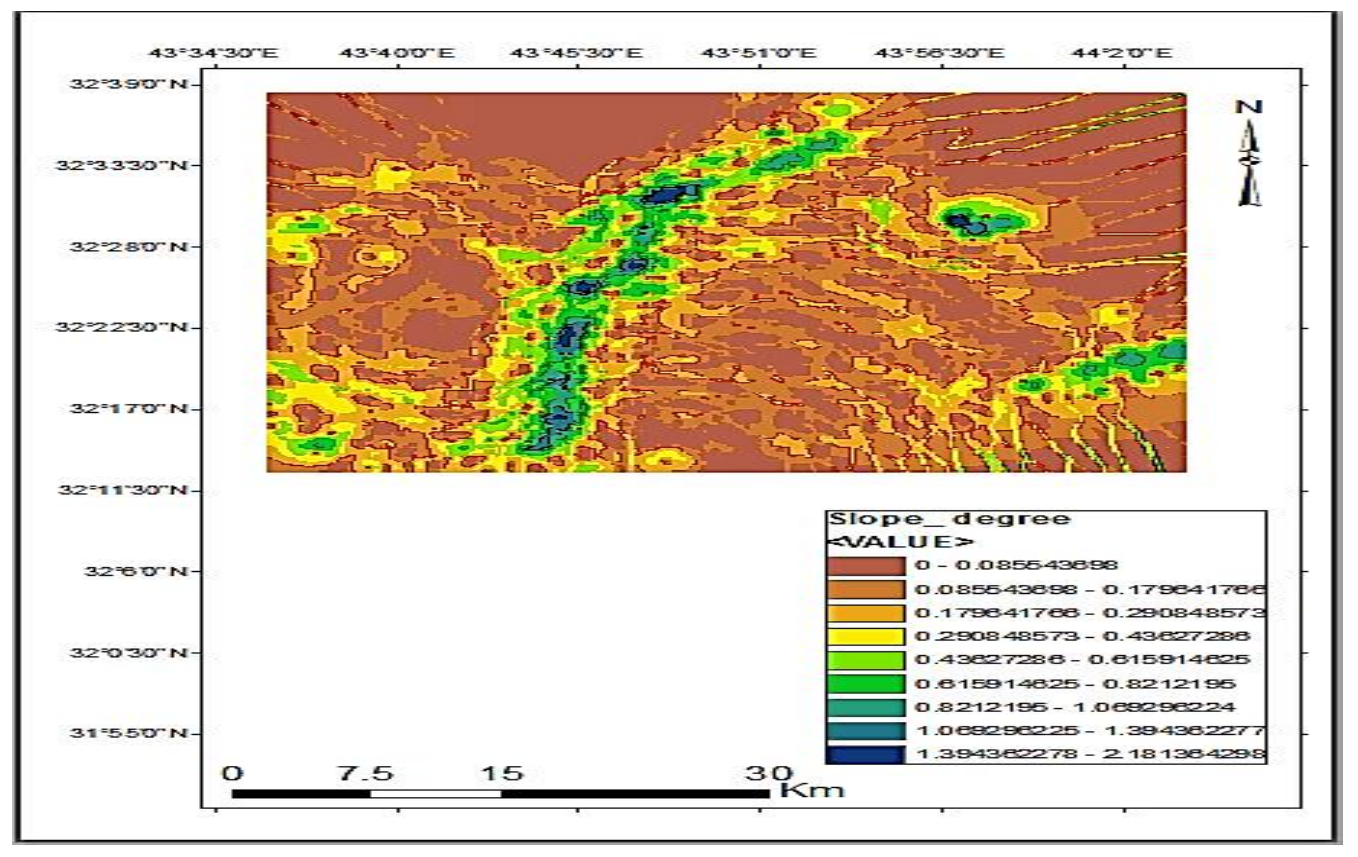

Figure 5. Slope map of the study area.

Aspect Map. Figure 6 shows the aspect map of the study area that was produced from the digital elevation model and ArcGIS software 10.8. From the aspect map, it is possible to know the cells towards the slope of the terrains study area, as the more significant part of the study area is towards the east, the northeast, and the northwest, while the small parts of the study area are towards the south, north and southwest, and a small part of the study area is flat.

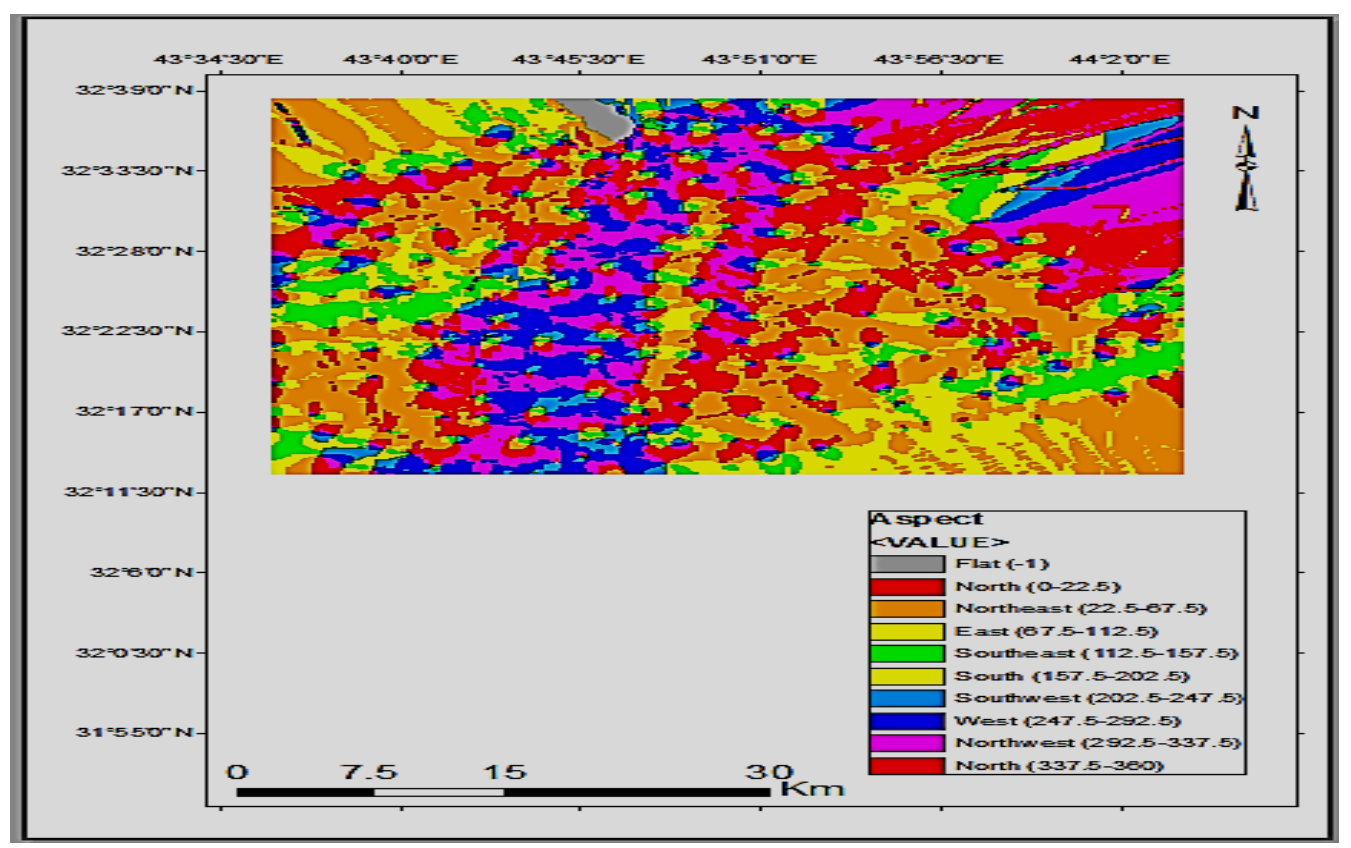

Figure 6. Aspect map of the study area.

Hill Shade Map. From the same DEM and using the ArcGIS software 10.8 and with the azimuth of the default light source in the software 315 degrees and the altitude of the light source 45 degrees, a Hill Shade map of the study area was created. The map showed a three-dimensional perspective of the terrain's study area, and Figure 7 indicates that the area is not flat and gradually rises from the north towards the south. 


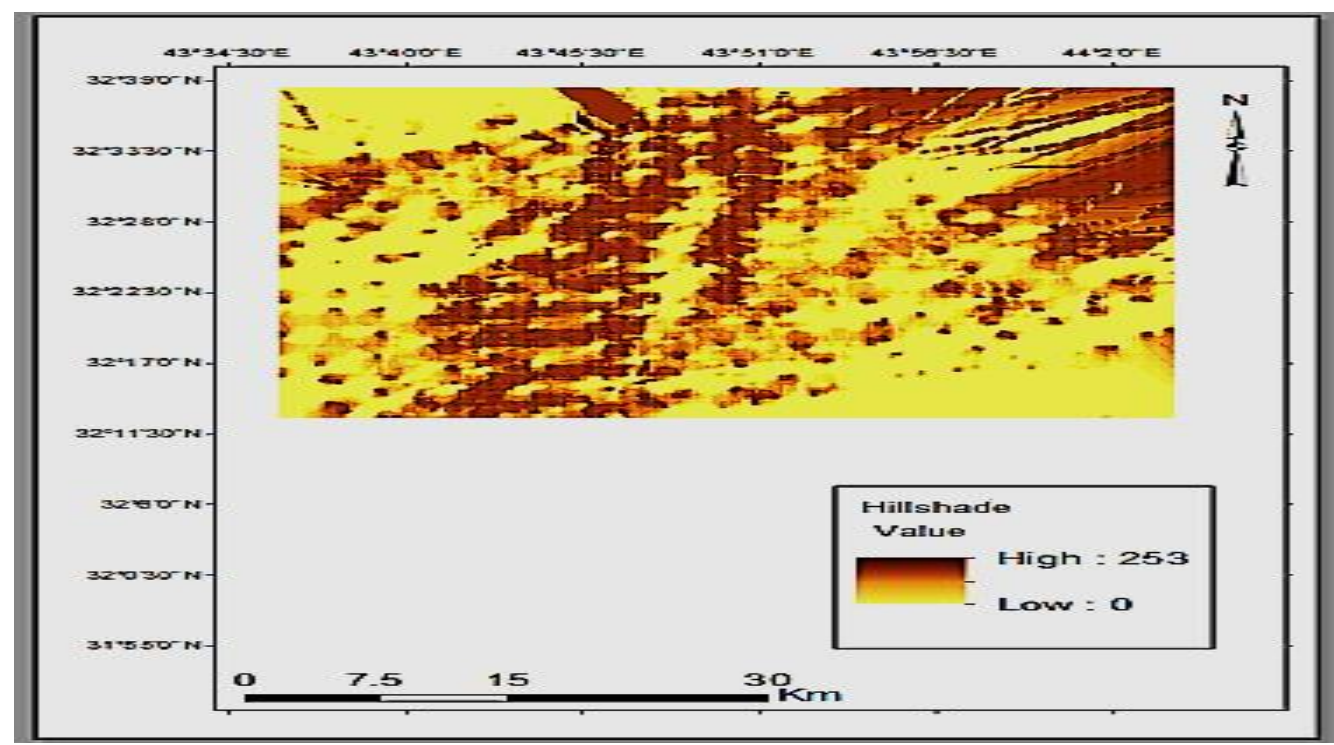

Figure 7. Hill shade map of the study area.

\section{Hydrological Analysis Results}

To obtain the results of the hydrologic analyzes, hydrologic analysis tools must be used from the ArcGIS software, which includes the following:

Fill. To treat outliers, for example, the irregular highs and lows of the digital elevation model for the study area, this is done using the filling process, where a digital elevation model is produced for the study area free from irregular values, as shown in Figure 8.

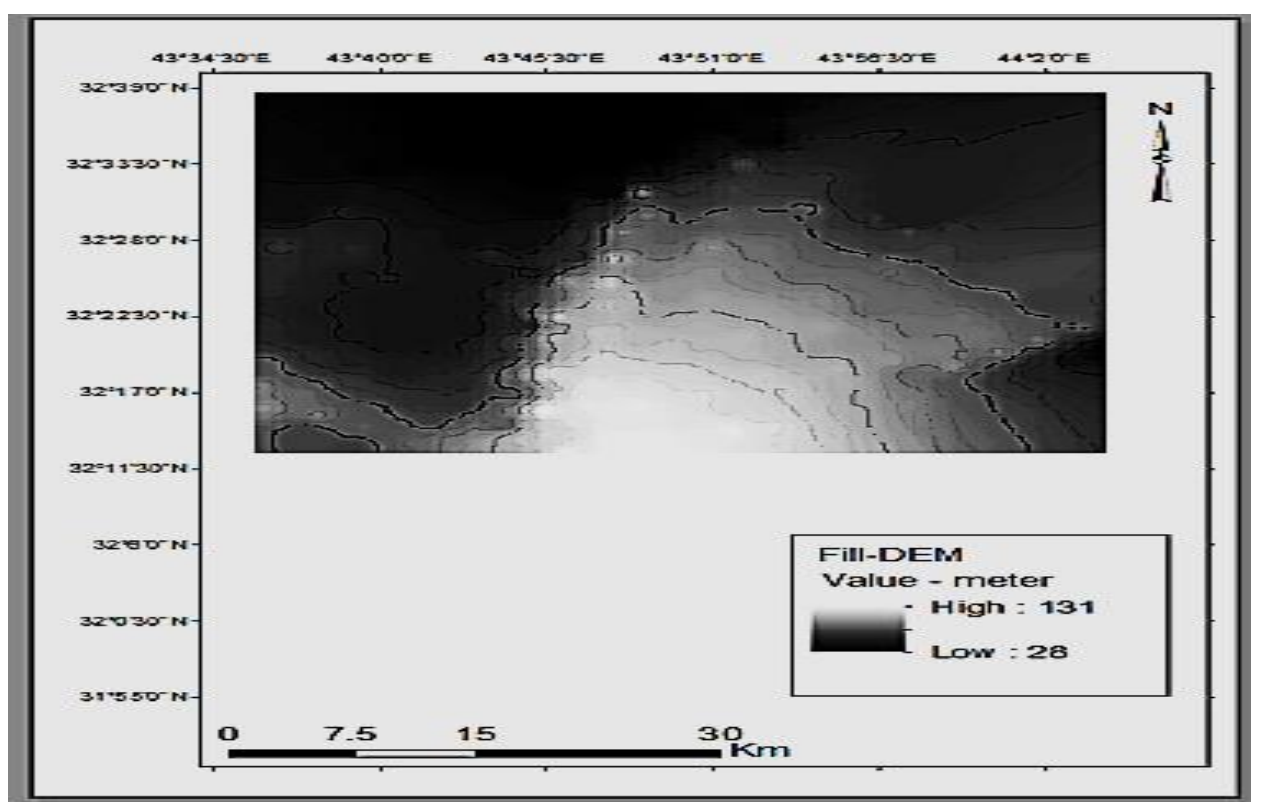

Figure 8. Fill-DEM map of the study area.

Flow Direction. A flow direction map was made from the digital elevation model of the study area after handling the outliers (highs or lows) through a process called (Fill ) [17]. In the Arc GIS software 10.8 , and treatment DEM from TIF to grid form that best in hydrologic analysis. The keys to the flow direction (direction coding) can be illustrated with the directions so that they are number 1: East, 2: Southeast, 4: South, 8: Southwest, 16: West, 32: Northwest, 64: North, 128: Northwest as shown in Figure 9. 


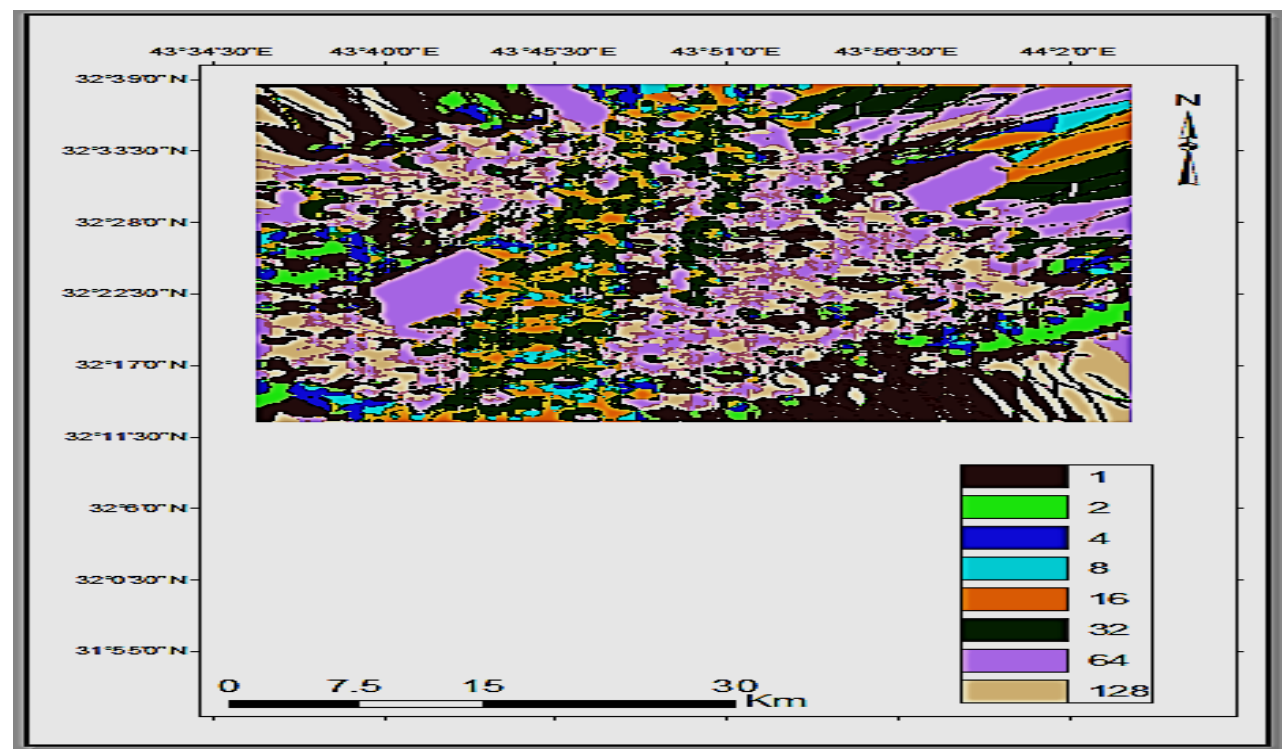

Figure 9. Flow direction map of the study area.

Flow Accumulation (conditional) Map. From the flow direction layer, a flow accumulation layer was produced for the study area using ArcGIS software 10.8. To increase the improvement of the flow accumulation layer of the study area, through the conditional process, which depends on the value of sensitivity where value was $>200$ and by stream feature treatment raster layer to vector layer as shown in Figure 10. The mean purpose from producing the condition map to produce a stream order map.

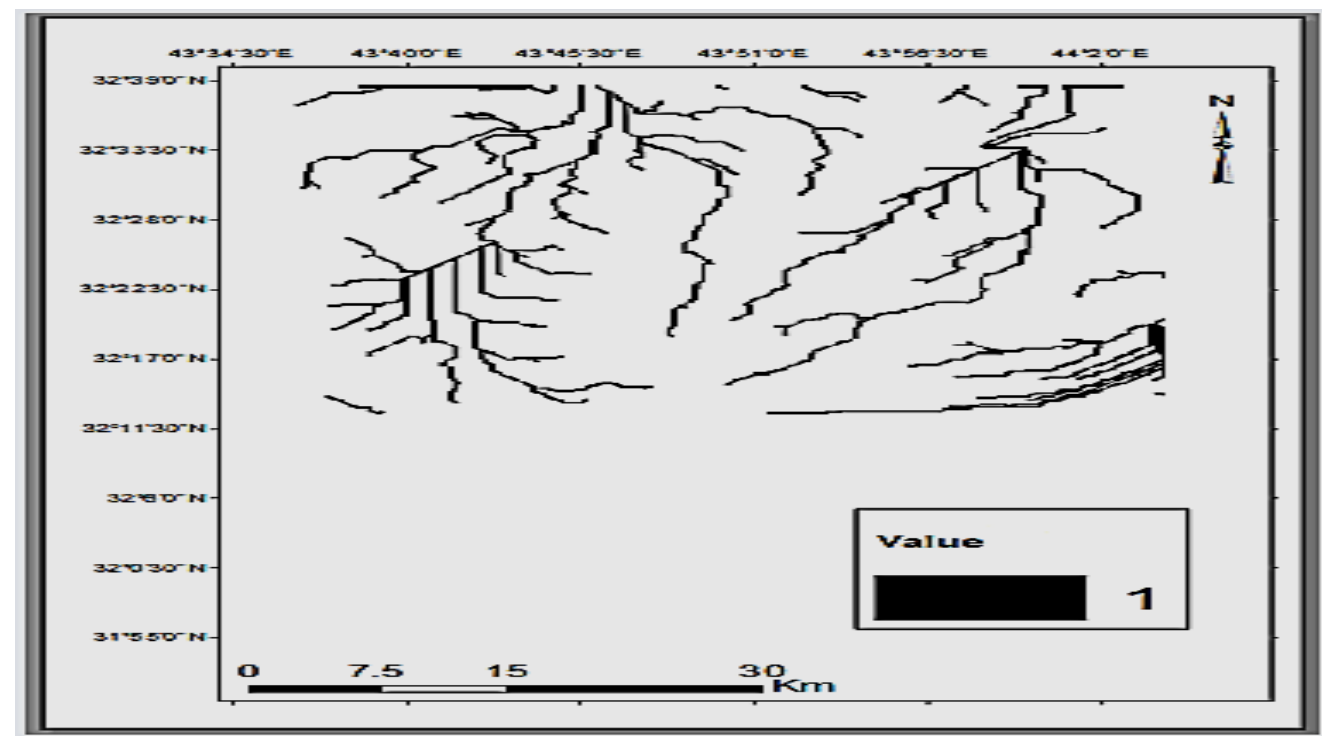

Figure 10. Flow accumulation (conditional) map of the study area.

Stream Order Map. The stream order map of the study area is produced using ArcGIS software 10.8 and using the Staler method [18], as shown in Figure 11. This map indicates the classified stream order is four order from 1 to 4 . This map aims to classify the sinks into order in terms of capacity where small sinks take (1) order, and when to meet with each other it takes the order (2) with the largest size of capacity and soon to the last order is (4) for the study area. 


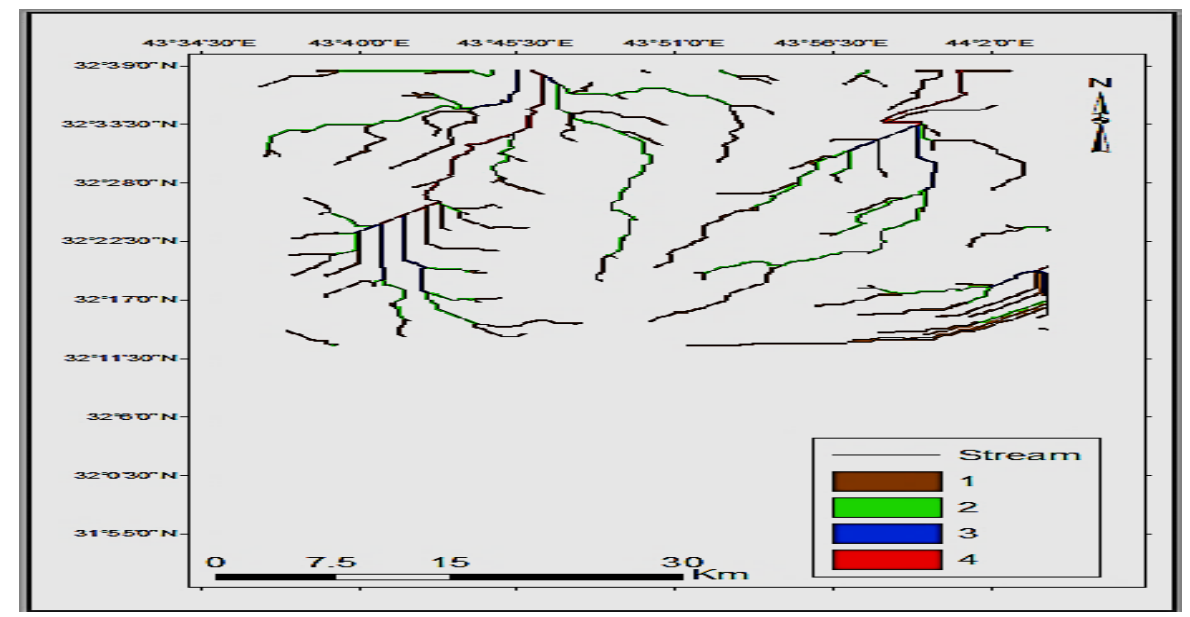

Figure 11. Stream order map of the study area.

Basin Map. The ArcGIS software defines the basins of the whole study area and other basins from the regions adjacent to the study area, as shown in Figure 12. Therefore, the determination of the main basins for the study area depends on the large basins and neglects the basins with a small area and from the basins map show (32) basin in the study area, but it can be possible to determine the main basins, where there are four begin. The main basins of the study area were determined using ArcGIS software and from the flow accumulation layer and the flow direction layer. This map can study the morphometric properties of each basin in the study area. A map of the basin was produced from one parameter, DEM, to determine the efficiency of this DEM in hydrological analysis.

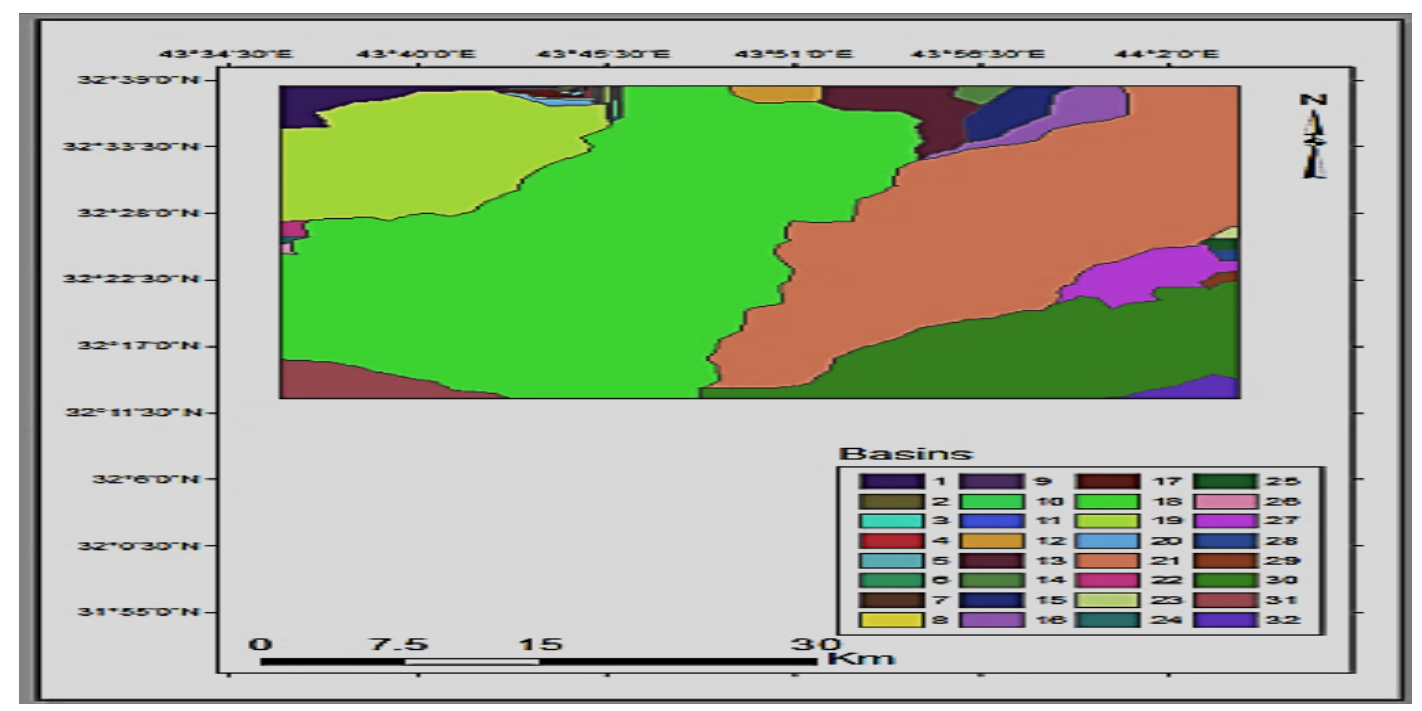

Figure 12. Basin map of the study area.

\section{Conclusions}

The field survey method of creating a (DEM) is a successful method in representing terrain, and its accuracy depends on the accuracy of the devices used in the field survey. Through GIS techniques, all appropriate processes can be performed to convert the old traditional topographic maps of Iraq into digital maps, which are easy to use and can be stored and updated at any time. The study area (western part of Karbala) is one of the areas characterized by a desert region and which suffers from water scarcity, especially in the dry season because of the lack of surface water. Hence, this research has proved the presence of basins produced from the rainwater collection, which can be used in watering and agriculture. Also, the study area can be settled and converted from a desert to an agricultural area by optimizing the area's water resources, such as the use of modern irrigation 
methods. This research can be used in all desert areas in Iraq and study its topographic and hydrological characteristics.

\section{References}

[1] Adham, A., Sayl, K.N., Abed, R., Abdeladhim, M.A., Wesseling, J.G., Riksen, M., Fleskens, L., Karim, U. and Ritsema, C.J., 2018. A GIS-based approach for identifying potential sites for harvesting rainwater in the Western Desert of Iraq. International Soil and Water Conservation Research, 6(4), pp.297-304.

[2] Nkeki, N.F. and Asikhia, M.O., 2014. Mapping and Geovisualizing Topographical Data Using Geographic Information System (GIS). Journal of Geography and Geology, 6(1), p.1.

[3] Jasem, M.S. and Odey, A.H., 2020. Positional Accuracy Assessment for Updating Authoritative Geospatial Datasets Based on Open Source Data and Remotely Sensed Images. Journal of Engineering, 26(2), pp.70-84.

[4] Nkeki, N.F. and Asikhia, M.O., 2014. Mapping and Geovisualizing Topographical Data Using Geographic Information System (GIS). Journal of Geography and Geology, 6(1), p.1.

[5] Bennett, D.A. and Armstrong, M.P., 2001. Fundamentals of geographic information systems (GIS). Manual of Geospatial Science and Technology, edited by J. Bossler, London: Taylor and Francis, pp.411-430.

[6] Kumar, R.S. and Ramana, G.V., 2017. Analysis of runoff through SCS-CN method for sustainable agriculture using remote sensing and gis modules. International Journal of Civil Engineering and Technology (IJCIET), 8(10), pp. 598-608

[7] Khemiri, S., Chenini, I., Saidi, S., Baamar, B., Mammou, A.B. and Zargouni, F., 2013. DEMBased GIS Algorithms and 3D Geospatial Mapping for Creation of Hydrogeological Models Data in Foussana Basin (Central Tunisia).

[8] Balasubramanian, A., 2017. Digital elevation model (DEM) in Gis. University of Mysore.

[9] Hashim, A.K. and Mohammed, E.J., 2016. Measurement of radon concentration and the effective dose rate in the soil of the city of Karbala, Iraq. J. Rad. Nucl. Appl, 1(1), pp.17-23.

[10] Salman, K.J., Hammed, Y.A. and Hussein, K.H., 2018. Hydrological Analysis of Al-Samawa Desert Using GIS. Int J Adv Technol, 9(198), p.2.

[11] Dawod, Gomaa M., 2018, Advanced Statistical and Spatial Applications (in Arabic). Cairo, Egypt.

[12] Hassan, W.H. and Khalaf, R.M., 2020, November. Optimum Groundwater use Management Models by Genetic Algorithms in Karbala Desert, Iraq. In IOP Conference Series: Materials Science and Engineering (Vol. 928, No. 2, p. 022141). IOP Publishing.

[13] Ali, A.H. and Jaber, H.S., 2020. Monitoring degradation of wetland areas using satellite imagery and geographic information system techniques. The Iraqi Journal of Agricultural Science, 51(5), pp.1474-1485.

[14] Najafi, P., Feizizadeh, B. and Navid, H., 2021. A Comparative approach of Fuzzy Object based image analysis and machine learning techniques which are applied to crop residue cover mapping by using sentinel-2 satellite and uav imagery. Remote Sensing, 13(5), p.937.

[15] Ikechukwu, M.N., Ebinne, E., Idorenyin, U. and Raphael, N.I., 2017. Accuracy assessment and comparative analysis of IDW, spline and kriging in spatial interpolation of landform (Topography): An experimental study. Journal of Geographic Information System, 9(03), p.354.

[16] Hussein, Z.E., 2016. Accuracy evaluation of digital elevation model created using handheld Global Positioning System receivers. Journal of Engineering, 22(6), pp.137-148. 
[17] Bera, A., Mukhopadhyay, B.P. and Das, D., 2018. Morphometric analysis of Adula River basin in Maharashtra, India using GIS and remote sensing techniques. Geo-spatial data in natural resources, pp.13-35.

[18] Kennedy, M.D., 2013. Introducing geographic information systems with ARCGIS: a workbook approach to learning GIS. John Wiley \& Sons. 